\title{
Light-dependent oxygen cycling measured by an oxygen-18 isotope dilution technique*
}

\author{
Todd M. Kana
}

Horn Point Environmental Laboratories, University of Maryland, Box 775, Cambridge, Maryland 21613, USA

\begin{abstract}
A new ${ }^{18} \mathrm{O}$ isotope dilution technique is presented and examples are given of the determination of true gross oxygen evolution (photosynthesis) and oxygen uptake (respiration) in plankton samples from estuarine surface waters and in the seagrass Zostera marina. The technique involves enriching dissolved oxygen with ${ }^{36} \mathrm{O}_{2}$, and measuring changes in isotope enrichment and oxygen concentration with time. It is relatively simple to apply, and less expensive than previously used ${ }^{18} \mathrm{O}$ methods. Oxygen uptake rates of plankton samples incubated under various light conditions ranged from 0.75 to 10 times that in darkness. Gross oxygen evolution rates determined by isotope dilution were from 0 to $80 \%$ higher than gross oxygen evolution rates calculated from parallel light and dark bottle experiments and ranged between 180 and $800 \mu \mathrm{MO}_{2}(\mu \mathrm{M} \mathrm{chl} \mathrm{a})^{-1} \mathrm{~h}^{-1}$. Ratios of gross oxygen uptake to gross oxygen evolution were between 0.12 and 0.67 and depended on both light intensity and sampling time. Occasionally, net oxygen evolution and isotope dilution occurred in darkened bottles, suggesting the existence of a non-photosynthetic process that produces new oxygen. In $Z$. marina, oxygen uptake at saturating light intensities was 4.7 times the rate in darkness. The data indicate the existence of significant, but variable, light stimulation of oxygen consumption in estuarine waters and higher rates of gross oxygen production than measured by the light and dark bottle technique.
\end{abstract}

\section{INTRODUCTION}

One of the earliest techniques for measuring metabolic activity in aquatic systems was the light and dark (L/D) bottle oxygen method (Gaarder \& Gran 1927). The method is simple and has been widely applied. Net changes in dissolved oxygen in illuminated and darkened water samples are used as a measure of gross and net production and respiration. In practice, interpretation of the results from this technique involves considerable uncertainty and has been the subject of a $40 \mathrm{yr}$ debate regarding analytical, methodological, and theoretical arguments (e.g. Peterson 1980, Williams et al. 1983, Smith et al. 1984).

One of the well-recognized and fundamental problems with the L/D bottle technique is the fact that it is incapable of measuring light-dependent respiration. Light-dependent oxygen uptake processes that have been regarded as being important include dark (mitochondrial) respiration (Turpin et al. 1988, Weger et al. 1989), photorespiration (Harris \& Piccinin 1977,

\footnotetext{
- Contribution no. 2112 from the Center for Environmental
} and Estuarine Studies, University of Maryland
Harris 1980), Mehler reaction (Raven \& Beardall 1981), respiration of heterotrophs stimulated by increased cycling of dissolved organic matter (Smith et al. 1986 , Lancelot \& Mathot 1985), and non-biological photochemical oxidation reactions (Gieskes \& Kraay 1982, Laane et al. 1985). If photorespiration, Mehler reaction activity, or any other light-dependent oxygen consuming reactions are occurring, true gross oxygen evolution and consumption rates will be underestimated by the L/D bottle technique. The actual magnitude and variability of this effect are only now being appreciated as a result of the development of isotope techniques that can separate the evolution and uptake fluxes. Bender and Grande (Bender et al. 1987, Grande 1988, Grande et al. 1989) recently measured true gross oxygen production and consumption rates using an $\mathrm{H}_{2}{ }^{18} \mathrm{O}$ method. At the extreme, they reported oxygen uptake rates in the light up to 10 times higher than the rate measured in darkness and gross oxygen production rates 2 times higher than that estimated by the $\mathrm{L} / \mathrm{D}$ bottle method.

Their incubation technique was the first application of ${ }^{18} \mathrm{O}$ as a tracer of true gross oxygen production and consumption in natural plankton communities. The 
method uses $\mathrm{H}_{2}{ }^{18} \mathrm{O}$ to trace the water splitting reaction (Hill reaction) of photosynthesis and as such, provides an accurate measurement of gross photosynthetic oxygen evolution. Gross oxygen consumption in the light is calculated from the difference between gross and net evolution, the latter determined from measured changes in total oxygen concentration during an incubation. Using an isotope ratio mass spectrometer and high precision $\mathrm{O}_{2}$ concentration determinations, the technique is sensitive enough to measure diurnal oxygen production and consumption of a few tenths of a umole $\mathrm{l}^{-1}$ (Grande 1988).

Development of the present ${ }^{18} \mathrm{O}$ technique was motivated by a desire to have a method that used smaller quantities of isotope and samples that could be analyzed on a quadrupole mass spectrometer. These andlyzers are relatively inexpensive as well as being small and durable enough to be used at sea. Also, the technique had to have greater sensitivity than the membrane inlet mass spectrometry technique used to study oxygen cycling in cultured algae (Hoch \& Kok 1963, Radmer \& Ollinger 1980). In this paper, I describe a new ${ }^{18} \mathrm{O}$ method, based on the principles of isotope dilution experiments, which satisfies these requirements.

\section{Principles of ${ }^{36} \mathrm{O}_{2}$ isotope dilution}

The principles of the ${ }^{36} \mathrm{O}_{2}$ isotope dilution technique parallel those used to measure ammonium (Blackburn 1979, Glibert et al. 1982), amino acid (Fuhrman 1987) and $\mathrm{CO}_{2}$ (Weisburd \& Laws 1988) cycling in marine systems and share the basic principles and assumptions of the membrane inlet mass spectrometry technique. The method assumes that the only source of 'new' dissolved oxygen is the Hill reaction of photosynthesis. New oxygen has an isotopic composition that reflects the random combination of oxygen atoms from 2 water molecules (i.e. evolved oxygen is $99.5 \%{ }^{32} \mathrm{O}_{2}$ ). In a system enriched with ${ }^{36} \mathrm{O}_{2}$, photosynthesis causes a progressive reduction in isotope enrichment (isotope dilution) of the dissolved oxygen. On the other hand, processes that consume oxygen (e.g. respiration, photorespiration, photochemistry, etc.) cause a depletion in the different oxygen isotopes in proportion to their relative concentrations. In practice, isotope discrimination by any of the processes is too small to be detected by this method and is consequently ignored. It is also assumed that intracellular or internal recycling of oxygen isotopes is insignificant. This assumption has been analyzed independently by a number of workers and is generally considered valid. Gross rates of oxygen uptake and evolution are calculated from a knowledge of the time-dependent changes in oxygen isotope enrichment and total dissolved oxygen concentration.

\section{MATERIALS AND METHODS}

Implementation of this new ${ }^{18} \mathrm{O}$ isotope dilution technique for studies of natural plankton required the development of a sample preparation and analysis scheme that would be benign to the organisms, allow for processing of multiple bottles in a given experiment, and allow for the measurement of the change of both the isotope enrichment and total oxygen concentration in a given sample with sufficient precision to resolve oxygen concentration changes in the order of a few umoles $\mathrm{l}^{-1} \mathrm{~h}^{-1}$. The technique would be most sensitive when all the dissolved oxygen in the sample at time 0 is labelled (e.g. as ${ }^{36} \mathrm{O}_{2}$ ), but it is not possible to substitute the normal oxygen entirely with ${ }^{36} \mathrm{O}_{2}$ without significant disturbance to the organisms. The sample preparation scheme thus used in this study refected compromises relating to desired sensitivity, organism handling, and sample processing.

Sample preparation. Approximately $10 \%$ of a water sample was vacuum filtered $(100 \mathrm{~mm} \mathrm{Hg})$ through a Whatman GF/F filter followed by a Nuclepore $0.2 \mathrm{um}$ membrane filter. This water was degassed under vacuum using a 2 -stage mechanical vacuum pump for ca 2 min and enriched with tracer by drawing a bubble (several $\mathrm{ml}$ ) of $98 \%{ }^{36} \mathrm{O}_{2}$ into a large volume gas-tight syringe with stopcock. Dissolution of the ${ }^{36} \mathrm{O}_{2}$ gas was facilitated by agitating the sample with a magnetic stir bar and applying manual pressure to the syringe plunger The water labelled with ${ }^{36} \mathrm{O}_{2}$ was then added back to the whole water sample. In practice, this procedure yielded an enrichment $\left[{ }^{36} \mathrm{O}^{2} /\left({ }^{32} \mathrm{O}_{2}+{ }^{36} \mathrm{O}_{2}\right)\right]$. of ca 0.20 and an increase in total oxygen concentration of ca $12 \%$. A cylindrical container with floating top was used for holding the bulk sample (typically 5 to $7 \mathrm{l}$ ). This minimized outgassing of ${ }^{36} \mathrm{O}_{2}$ while the whole sample was gently stirred and dispensed among sample flasks.

Sample borosilicate flasks were of 2 types. Iodine flasks $(125 \mathrm{ml})$ were used for total dissolved oxygen concentration measurements by Winkler titration. Screw-cap flasks $(125 \mathrm{ml})$ were used for isotope ratio measurements. These latter flasks were capped with a custom-built Teflon vacuum valve (Eldex), similar in design to a Mininert valve, allowing a sample to be contained without a head space and degassed without air contamination. Oxygen concentrations and isotope enrichments were determined for duplicate or triplicate bottles at time 0 and for duplicate bottles at incubation end-points.

Isotope enrichment determinations. Water samples were degassed and oxygen isotope ratios (mass 32 and 
36) were determined directly by mass spectrometry At the end of an incubation, flasks were either degassed immediately or placed in a refrigerator for short periods of time in darkness. In theory, this prevents changes in the isotope ratio - but see 'Results' In general, experiments were designed so that a sample was analyzed within $1 \mathrm{~h}$ of the end of its incubation period. Gas extraction under vacuum was facilitated by vigorously mixing the sample with a magnetic stir bar that was inserted into the flask at the time of sample preparation. The evolved water vapor and $\mathrm{CO}_{2}$ were frozen out using a liquid nitrogen cold trap and the gases were collected on a molecular sieve (5A). The extraction proceeded until $>98 \%$ of the gas was collected as estimated by the residual pressure in the vacuum line. The collected gas, composed of nitrogen, oxygen, and argon, was liberated into a section of the vacuum line connected to the mass spectrometer.

Mass spectrometry was carried out with a Balzers QMG-420 quadrupole mass spectrometer with QMS420 control unit. Ion intensities of molecular oxygen (mass 32 and 36) were measured directly. A display of the time course of mass ratios was used to determine when gas flow through the analyzer reached steadystate; final ratios were taken as the mean of measurements taken over a $30 \mathrm{~s}$ period. Using this method, $\mathrm{O}_{2}: \mathrm{N}_{2}$ ratios of air standards varied in the fourth decimal place. Calibration of the mass spectrometer for the ${ }^{36} \mathrm{O}_{2}:{ }^{32} \mathrm{O}_{2}$ ratio was done using quantitative injections of air and high enrichment ${ }^{36} \mathrm{O}_{2}$ into the vacuum line. Partial pressures of nitrogen, argon, carbon dioxide, and water vapor in the primary gases were determined by mass spectrometry using air as a calibration standard and factored into the calculation of the final oxygen isotope partial pressures. Analyzer response was linear up to at least $45 \%{ }^{36} \mathrm{O}_{2}$ with a slope of $1.003\left(\mathrm{r}^{2}=\right.$ $0.998)$.

Oxygen concentration and chlorophyll a determinations. Dissolved oxygen concentrations were measured by Winkler titration (Strickland \& Parsons 1972) using a Metrohm 655 automatic titrator. End points were detected visually using a starch indicator solution.

Duplicate chlorophyll a (chl a) determinations were made on aliquots of the diluted sample filtered onto $\mathrm{GF} / \mathrm{F}$ filters. Filters were ground in cold $90 \%$ acetone and pigments extracted for 2 to $5 \mathrm{~h}$ in darkness under refrigeration. ChI a was determined spectrophotometrically using the equations in Parsons et al. (1984).

Calculations. Gross oxygen uptake $\left(\mathrm{U}_{0}\right)$ and gross oxygen evolution $\left(E_{0}\right)$ were calculated using the isotope dilution equations formulated by Blackburn (1979). $E_{0}$ and $U_{0}$ were calculated as:

$$
E_{0}=\frac{C_{t}-C_{0}}{t} \quad\left[\frac{\ln \left(R_{0} / R_{t}\right)}{\ln \left(C_{1} / C_{0}\right)}\right]
$$

$$
\mathrm{U}_{\mathrm{o}}=\mathrm{E}_{\mathrm{o}}-\frac{\mathrm{C}_{\mathrm{t}}-\mathrm{C}_{\mathrm{o}}}{\mathrm{t}}
$$

where $C_{1}$ and $C_{0}=$ concentrations of dissolved oxygen at time $t$ and time 0 respectively; $R_{1}$ and $R_{0}=$ the isotope enrichments [mass $36 /$ (mass $36+$ mass 32 )] at times $t$ and 0 . Oxygen concentrations and enrichments were taken as the average of duplicate or triplicate measurements.

When biomass was measurable but unevenly distributed among sample flasks (e.g. measurements of $E_{0}$ and $U_{o}$ in Zostera marina leaf segments), all data were corrected to a grand mean biomass. The procedure involved 2 steps. First, the oxygen concentration change (delta $\mathrm{O}_{2}$ ) in the Winkler flasks was corrected by proportioning delta $\mathrm{O}_{2}$ by the ratio of mean biomass:sample biomass. This gave a corrected time $t$ oxygen concentration in the Winkler flask. Partially corrected $\mathrm{E}_{\mathrm{O}}$ and $\mathrm{U}_{0}$ rates were then calculated using the isotope dilution equations. Second, the ${ }^{36} \mathrm{O}_{2}$ enrichment of the isotope ratio sample at time $t$ was corrected by using (a) biomass-corrected delta $\mathrm{O}_{2}$-values, calculated as in the first step, but using the biomass in the isotope ratio bottle, and (b) the isotope enrichment that is the solution of the rearranged isotope dilution equation using the $E_{0}$ and $U_{0}$ values calculated in the first step.

Sampling procedures and incubation conditions. The experiments reported here involved plankton samples collected by bucket from the Choptank River at or near Horn Point Environmental Laboratories, Maryland, USA. Salinity was 8 to $12 \mathrm{ppt}$. Unless other. wise indicated, water was initially screened through $125 \mu \mathrm{m}$ Nitex netting and returned to the laboratory for processing. Morning samples were collected before 07:30 h and incubations always began within 90 min of sample collection. Incubations were of 2 types: under sunlight (attenuated with fiberglass window screens) and under controlled light conditions using cool-white fluorescent tubes. Scalar irradiance $(400$ to $700 \mathrm{~nm})$ was measured with a Biospherical QSL-100. Temperature was maintained within $1{ }^{\circ} \mathrm{C}$ of the river water temperature by either suspending the bottles in situ or placing the bottles in a temperature-controlled enviromment room.

For a size fractionation experiment, a water sample was collected prior to dawn and screened through 202 um Nitex net and a subsample through $10 \mu \mathrm{m}$ Nitex net. Incubation duration was $4 \mathrm{~h}$. The rates associated with a 10 to $202 \mu \mathrm{m}$ fraction were calculated by subtracting the $10 \mu \mathrm{m}$ fraction rates from the $202 \mu \mathrm{m}$ fraction rates

Zostera marina incubations used 10 leaf segments ( $2 \mathrm{~cm}$ long) per bottle. Leaf segments were immersed in synthetic seawater (Instant Ocean) made to $20 \mathrm{ppt}$ 
salinity. Bottles were incubated in temperature-controlled tanks under natural sunlight attenuated by fiberglass window screens. After the experiment, leaf segments were recovered and total leaf area determined by planimetry using a Li-Cor LI-3100 leaf area meter.

\section{RESULTS}

Data are presented for 3 different experimental conditions: Choptank River plankton from summer and fall, and natural macrophytes. This demonstrated the magnitude of $\mathrm{O}_{2}$ cycling rates that can be measured with this technique. Representative examples are given of the time course of oxygen labelling, differences in morning and aftemoon oxygen uptake and evolution, size fraction differences, and the effects of light intensity

Time courses of isotope enrichment for samples collected in August and October (Fig. 1) are shown to illustrate the decrease in ${ }^{36} \mathrm{O}_{2}$ enrichment when chl a concentrations in the Choptank River were high (37 $\mu \mathrm{g}$ $\left.\mathrm{l}^{-1}\right)$ in August and low $\left(5.8 \mu \mathrm{g}^{-1}\right)$ in October. In the August experiment (Fig. 1 upper), ${ }^{36} \mathrm{O}_{2}$ enrichment of samples incubated under unattenuated natural sunlight declined from 21.3 to $12.0 \%$ over a $7.5 \mathrm{~h}$ period. Isotope dilution was also observed in darkened bottles on this day. In the October experiment, using artificial light incubations ( $365 \mu \mathrm{E} \mathrm{m} \mathrm{m}^{-2} \mathrm{~s}^{-1}$ ), isotope dilution was slightly less than 2 percentage points. Isotope dilution also occurred in darkened bottles on this date but to a lesser extent than in August. Dark bottle corrections were not applied to the light bottle isotope dilution data presented in this paper.

Rates of oxygen uptake and evolution were compared between freshly collected morning and afternoon samples. Samples were suspended at a depth of $30 \mathrm{~cm}$ for $4 \mathrm{~h}$ beginning at 09:00 h and $3.5 \mathrm{~h}$ beginning at $12: 10 \mathrm{~h}$. The sky was cloudless throughout the day, but turbidity of the water increased dramatically during the afternoon incubation (note, the higher chl a concentrations in that water sample) making the bottles nearly invisible from the surface for about half the incubation period. Comparable maximal $E_{0}$ rates $[750$

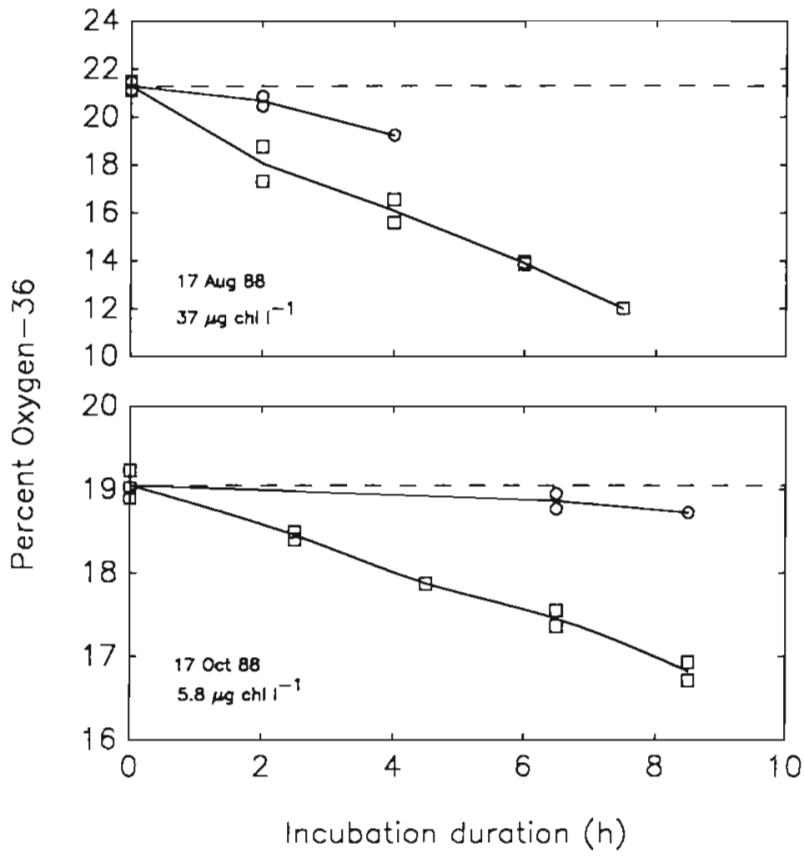

Fig. 1. Time course for isotope dilution on 2 sampling dates. ( $\square)$ Percent enrichment of ${ }^{36} \mathrm{O}_{2}$ in illuminated bottles; $(0)$ percent enrichment of ${ }^{36} \mathrm{O}_{2}$ in darkened bottles

to $778 \mu \mathrm{M} \mathrm{O} \mathrm{O}_{2}(\mu \mathrm{M} \text { chl a })^{-1} \mathrm{~h}^{-1}$ ] were observed in unscreened bottles in both morning and afternoon incubations (Table 1). These were 12 to $14 \%$ higher than gross rates determined by the $\mathrm{L} / \mathrm{D}$ bottle technique. Oxygen uptake in the light $\left(\mathrm{U}_{0}\right)$ was 1.9 to 2.2 times the rate in darkness for 3 of 4 incubation conditions. Only under dim light in the afternoon sample was the rate in the light lower than the rate in darkness. Gross uptake to evolution ratios $\left(\mathrm{U}_{0}: \mathrm{E}_{\mathrm{o}}\right)$ were 0.20 to 0.28 , and were approximately twice as high as the ratios calculated from the $\mathrm{L} / \mathrm{D}$ bottle experiment.

In the size fractionation experiment, most of the chl a $(84 \%$ ) passed through the $10 \mu \mathrm{m}$ net (Table 2). Gross oxygen evolution $\left(\mathrm{E}_{0}\right)$ was higher in the small size fraction, but not proportionately as high as the chl a content, indicating that the larger phytoplankton had higher chl a-specific rates $[259$ vs $840 \mu \mathrm{M} \mathrm{O}$ ( $(\mu \mathrm{M}$ chl a) ${ }^{-1} \mathrm{~h}^{-1}$ in the $0-10$ and $10-202 \mu \mathrm{m}$ fractions, respectively]. $E_{0}$ was 30 and $45 \%$ higher than the L/D bottle

Table 1. Chlorophyll a concentration, percent incident solar radiation, and oxygen cycling rates (see Fig. 2 for definitions) for samples collected and incubated at 2 times on August 26

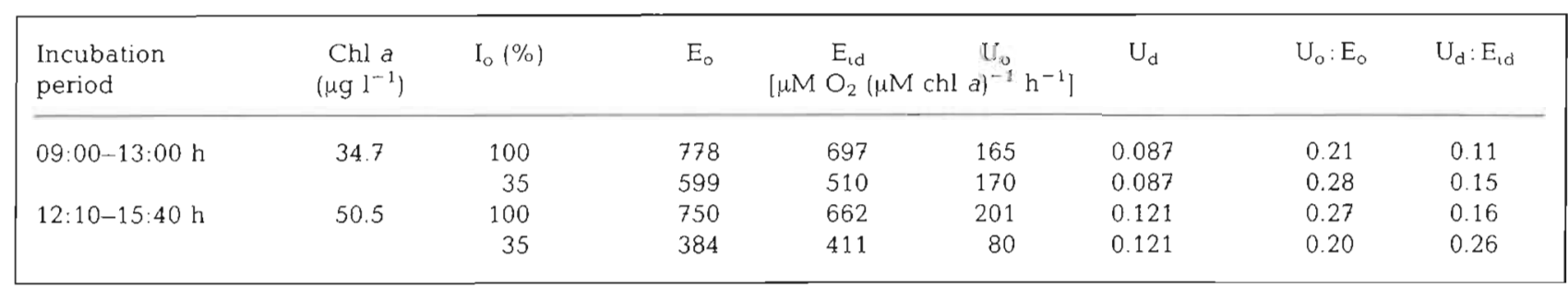


Table 2. Oxygen cycling rates (see Fig. 2 for definitions) and chlorophyll a concentrations for 2 size fractions collected on July 13

\begin{tabular}{|cccccccc}
\hline $\begin{array}{c}\text { Size fraction } \\
(\mu \mathrm{m})\end{array}$ & Chl a $\left(\mu \mathrm{g} \mathrm{l}^{-1}\right)$ & $\mathrm{E}_{\mathrm{o}}$ & $\begin{array}{c}\mathrm{E}_{\mathrm{ld}} \\
\left(\mu \mathrm{mol} \mathrm{l} \mathrm{l}^{-1} \mathrm{~h}^{-1}\right)\end{array}$ & $\mathrm{U}_{\mathrm{o}}$ & $\mathrm{U}_{\mathrm{o}}: \mathrm{E}_{\mathrm{o}}$ & $\mathrm{U}_{\mathrm{d}}: \mathrm{E}_{\mathrm{id}}$ \\
\hline $0-10$ & 19.6 & 5.6 & 4.3 & 2.7 & 1.3 & 0.48 & 0.32 \\
$10-202$ & 3.7 & 3.5 & 2.4 & 1.7 & 0.7 & 0.50 & 0.28 \\
\hline
\end{tabular}

Table 3. Ratios of oxygen cycling rates (see Fig. 2 for definitions) for data presented in Fig. 2

\begin{tabular}{|ccrc|}
\hline $\begin{array}{c}\text { Light intensity } \\
\left(\mu \mathrm{E} \mathrm{m}^{-2} \mathrm{~s}^{-1}\right)\end{array}$ & $\mathrm{E}_{\mathrm{o}}: \mathrm{E}_{\mathrm{id}}$ & $\mathrm{U}_{\mathrm{o}}: \mathrm{U}_{\mathrm{\textrm {d }}}$ & $\mathrm{U}_{\mathrm{o}}: \mathrm{E}_{\mathrm{o}}$ \\
\hline 35 & 2.4 & 7.7 & 0.68 \\
75 & 1.9 & 8.7 & 0.52 \\
150 & 1.4 & 7.2 & 0.34 \\
285 & 1.6 & 10.5 & 0.44 \\
385 & 1.5 & 9.7 & 0.38 \\
\hline
\end{tabular}

estimate of gross evolution $\left(E_{1 d}\right)$ in the small and large size fractions, respectively. The effect of light on oxygen consumption was pronounced with gross consumption rates $\left(\mathrm{U}_{\circ}\right)$ being 2.0 and 2.6 times the dark respiration rate in the small and large fractions, respectively. This resulted in significant differences in the uptake: evolution ratios between the isotope and L/D bottle techniques (Table 2), but not between size fractions.

Effects of light intensity on $\mathrm{U}_{0}, \mathrm{E}_{0}$, and $\mathrm{E}_{\text {ld }}$ were determined in constant light incubations on a sample collected in October which contained $4.8 \mu \mathrm{g} \mathrm{chl} \mathrm{a} \mathrm{l}^{-1}$.

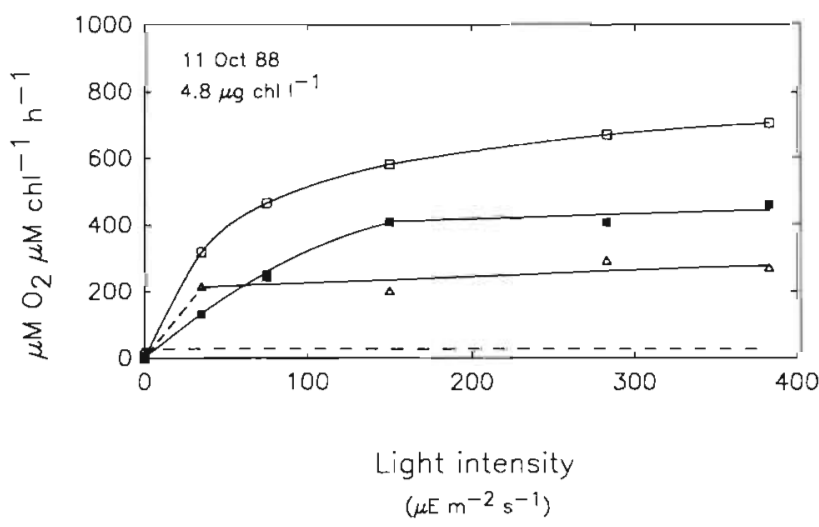

Fig. 2. Rates of oxygen uptake and evolution (absolute values) as a function of incubation light intensity. (ㅁ) Gross oxygen evolution $\left(E_{0}\right)$ measured by isotope dilution; ( $)$ gross oxygen evolution ( $E_{\text {ld }}$ ) measured by L/D bottle experiments; ( $\Delta$ ) gross oxygen uptake $\left(\mathrm{U}_{0}\right)$ measured by isotope dilution; dashed line: oxygen uptake rate measured in darkness $\left(\mathrm{U}_{\mathrm{d}}\right)$
Table 4. Zostera marina. Oxygen cycling rates (see Fig. 2 for definitions) in leaf pieces incubated under attenuated natural solar radiation

\begin{tabular}{|c|c|c|c|c|c|c|}
\hline 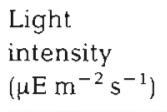 & $\begin{array}{c}E_{0} \\
1\end{array}$ & $\begin{array}{l}\mathrm{E}_{\mathrm{td}} \\
1 \mathrm{O}_{2} \mathrm{~d}\end{array}$ & $\begin{array}{r}U_{0} \\
-2 \mathrm{mir}\end{array}$ & $\mathrm{U}_{\mathrm{d}}$ & $\mathrm{U}_{0}: \mathrm{E}_{0}$ & $\mathrm{U}_{\mathrm{d}}: \mathrm{E}_{\mathrm{td}}$ \\
\hline 0 & 0.02 & - & 0.21 & 0.16 & - & - \\
\hline 35 & 1.00 & 0.70 & 0.47 & - & 0.47 & 0.22 \\
\hline 235 & 1.32 & 0.92 & 0.51 & - & 0.39 & 0.17 \\
\hline 1045 & 1.44 & 0.85 & 0.75 & - & 0.52 & 0.18 \\
\hline
\end{tabular}

$E_{\circ}$ exhibited a hyperbolic response and approached light saturation at the highest experimental intensity (385 $\left.\mu \mathrm{E} \mathrm{m}^{-2} \mathrm{~s}^{-1}\right)$. The maximum measured rate was 706 $\mu \mathrm{M} \mathrm{O}_{2}(\mu \mathrm{Mchl} a)^{-1} \mathrm{~h}^{-1}$. The maximum $\mathrm{E}_{\mathrm{o}}$ was $53 \%$ higher than $\mathrm{E}_{\mathrm{ld}}$. In addition, the initial slope of the $\mathrm{E}$ vs irradiance response, a measure of the light harvesting efficiency of photosynthesis, was significantly higher [8.9 vs 35.8 $\mu \mathrm{MO}_{2}(\mu \mathrm{M} \mathrm{chl} a)^{-1} \mathrm{~h}^{-1}\left(\mu \mathrm{E} \mathrm{m}^{-2} \mathrm{~s}^{-1}\right)^{-1}$ ] for $\mathrm{E}_{\mathrm{o}}$ than for $E_{1 d}$. This difference was related to the relationship between light intensity and light-dependent oxygen uptake $\left(\mathrm{U}_{0}\right)$. $\mathrm{U}_{0}$ was 7 to 10 times the rate of oxygen uptake in darkness ( $\left.U_{d}\right)$ (Fig. 2, Table 3) at every irradiance investigated and showed a slight tendency to increase at iradiances above $35 \mu \mathrm{E} \mathrm{m} \mathrm{m}^{-2} \mathrm{~s}^{-1}$, the lowest light intensity used in this experiment. $\mathrm{U}_{0}: \mathrm{E}_{0}$ ratios ranged between 0.34 and 0.68 and exhibited an inverse relationship with light intensity (Table 3 ).

Lastly, an experiment with the marine angiosperm, Zostera marina, is presented. Z. marina leaf segments were incubated under natural light that was attenuated to 1045,235 , and $35 \mu \mathrm{E} \mathrm{m}{ }^{-2} \mathrm{~s}^{-1}$ (measured at the midpoint of the incubation) and in darkness (Table 4). At all intensities, $E_{0}$ was higher than $E_{l d}$ by from 43 to $69 \%$, with the highest intensity eliciting the greatest difference. The maximum $\mathrm{E}_{\mathrm{o}}$ rate of $1.44 \mu \mathrm{mol} \mathrm{\textrm {dm } ^ { - 2 }}$ $\min ^{-1}$ was at $1045 \mu \mathrm{E} \mathrm{m} \mathrm{m}^{-2} \mathrm{~s}^{-1}$. Oxygen uptake was significantly higher in the light than in darkness and increased from 0.21 to $0.75 \mu \mathrm{mol} \mathrm{O}_{2} \mathrm{dm}^{-1} \mathrm{~min}^{-1}$ at intensities from 0 to $1045 \mu \mathrm{E} \mathrm{m}^{-2} \mathrm{~s}^{-1}$. Uptake : evolution ratios were also greater when measured by the isotope technique. $\mathrm{U}_{\mathrm{o}}: \mathrm{E}_{\mathrm{o}}$ ranged from 0.39 to 0.52 compared to 0.17 to 0.22 for $U_{\mathrm{d}}: \mathrm{E}_{\mathrm{ld}}$ ratios. 


\section{DISCUSSION}

\section{Methodological considerations}

The ${ }^{18} \mathrm{O}$ isotope dilution technique can be a satisfactory alternative to the $\mathrm{H}_{2}{ }^{18} \mathrm{O}$ method when gross productivities exceed ca $1 \mu \mathrm{mol} \mathrm{O}_{2} \mathrm{~h}^{-1}$ (assuming a signal to noise ratio of $5,300 \mu \mathrm{mol} \mathrm{O} \mathrm{I}^{-1}, 20 \%$ enrichment, $\mathrm{U}_{0}: E_{0}=0.3$, and $12 \mathrm{~h}$ incubations). Limits to the precision of the technique were set by the sample preparation scheme and not the analytical methods. Two factors were important. First, for water containing high biomass and particularly when dinoflagellates were abundant, continual stirring of the whole water sample was necessary while dispensing it among sample bottles. Because the stirring facilitated outgassing of the ${ }^{36} \mathrm{O}_{2}$, a floating cap was placed on the bulk sample. With caution, the fortieth bottle filled was typically no more than $0.3 \%$ lower in enrichment than the first bottle. Since this was a systematic deviation, triplicate time 0 enrichments were measured on bottles filled at the beginning, middle and end of the line of flasks. Second, the process of pouring the sample water into the flasks introduced a random error. Usually, this variation could be held to within $0.05 \%$ of the mean percentage as determined by preparing distilled water samples. In practice, and given the present limitations, the isotope dilution technique can be used in typical estuarine and productive coastal environments when chl a concentrations exceed ca $3 \mu \mathrm{g} \mathrm{l}{ }^{-1}$.

\section{Oxygen evolution in darkness}

A basic assumption of the isotope dilution technique is that new oxygen is derived solely from photosynthesis. Occasional findings of isotope dilution in the dark, however, suggested that this assumption is invalid. For the following reasons it is thought that isotope dilution in the dark was not due to analytical error. First, the magnitude of the decrease was greater than the expected analytical error. Second, the dilution increased with time up to at least $24 \mathrm{~h}$ (data not shown). Third, isotope dilution was never observed in distilled water samples incubated for up to $24 \mathrm{~h}$. Fourth, an increase in the mass 32 signal caused by a fragment of an unknown organic compound was unlikely, because such compounds would be removed by the liquid nitrogen trap prior to analysis. Lastly, net increases in dissolved oxygen were measured independently in darkened bottles that were incubated in parallel with the isotope ratio bottles. This last aspect (net oxygen production in darkness) has been reported previously (e.g. Dugdale \& Wallace 1960,
Vollenweider 1969, Pamatmat 1988), although it has not been studied systematically.

The source of the oxygen in darkness has not been identified unequivocally, but Pamatmat (1988) has suggested that it is from the breakdown of hydrogen peroxide. This would be consistent with the observed isotope dilution in dark bottles if an ambient pool of $\mathrm{H}_{2} \mathrm{O}_{2}$ broke down to $\mathrm{O}_{2}$ and $\mathrm{H}_{2} \mathrm{O}$ during the course of the incubation. Hydrogen peroxide has been measured in seawater at concentrations typically on the order of tens to a few hundred nM (Van Baalen \& Marler 1966, Moffett \& Zika 1983, Zika et al. 1985, Miller \& Kester 1988) with a lifetime assumed to be on the order of 10 to 200 h (Palenik et al. 1987. Petasne \& Zika 1987). Yet, to account for the observed oxygen evolution in the present study, the standing stock and turnover of $\mathrm{H}_{2} \mathrm{O}_{2}$ would have to be higher. Significantly, Helz \& Kieber (1985) reported $\mathrm{H}_{2} \mathrm{O}_{2}$ concentrations in the Chesapeake Bay in July that were in the $\mu \mathrm{M}$ range (mean was $2 \mu \mathrm{M}$ ). Moreover, it is likely that our experiments accelerated $\mathrm{H}_{2} \mathrm{O}_{2}$ destruction because of contact with the walls of the glass incubation bottles and the presence of high concentrations of particulate material (Szymczak \& Waite 1988).

Whatever the mechanism was that led to apparent net oxygen evolution in darkness, it is necessary to recognize that it may be present, albeit at a lower rate, in dark bottle samples that exhibited net oxygen consumption. This would result in an under-estimate of the actual in situ dark respiration rate and an over-estimate of the magnitude of the light effect on oxygen uptake. The resulting error can be large if the dark gross evolution rate approaches the dark gross consumption rate. Thus, the estimated dark respiration rate $\left(U_{d}\right)$ would approach 0 and the index of light stimulation $\left(U_{1}: U_{d}\right)$ would approach infinity. This potential effect could not be evaluated in the present study

\section{Oxygen cycling rates}

Despite the uncertainties described above, it is apparent that oxygen cycling in the light can be significantly faster than that indicated from traditional L/D bottle measurements. Gross oxygen uptake rates ( $\mathrm{U}_{\circ}$ ) were typically from 25 to $60 \%$ of the gross oxygen evolution. rates $\left(E_{o}\right)$, compared to 10 to $30 \%$ when measured by the $\mathrm{L} / \mathrm{D}$ bottle technique. This was primarily due to significantly enhanced rates of oxygen uptake in the light, but also enhanced gross oxygen evolution rates. Similar general conclusions come from the cumulative work of Bender, Grande and colleagues (Bender et al. 1987. Grande 1988, Grande et al. 1989) who studied estuarine, coastal and open ocean environments using the $\mathrm{H}_{2}{ }^{18} \mathrm{O}$ method. 
Oxygen consumption rates have been observed to be as high as 10 times the rate measured in darkness (Bender et al. 1987; Table 3), though they are more typically 2- to 3 -fold higher and occasionally lower than the dark rate. As described in the previous section, the sometimes large stimulation of oxygen uptake may be due to our underestimating the dark respiration rate and not overestimating the light respiration rate (note that the dark respiration rate is not used in the determination of the light respiration rate). In fact, oxygen uptake to evolution ratios $\left(\mathrm{U}_{0}: \mathrm{E}_{\mathrm{o}}\right)$ are within the range of expectation. In the cases where light respiration was $>4$ times the dark rate, gross oxygen uptake was from 33 to $68 \%$ of the production rate (Tables 3 and 4). This is the same range of values previously reported for cultured algae (Bunt 1965, Peltier \& Thibault 1985, Sueltemeyer et al. 1986, Grande et al. 1989, Weger et al. 1989) and natural plankton samples (Bender et al. 1987. Grande 1988) and does not lead one to suspect that the light respiration measurements were significantly overestimated.

Two factors that were investigated, light intensity and organism size-class, influenced the oxygen cycling rates. Gross photosynthetic oxygen evolution did not saturate as early (with respect to increasing light intensity) as net oxygen evolution, indicating that the oxygen uptake reaction(s) increased with light intensity. This has also been seen in cyanobacteria, chlorophytes, and rhodophytes (Hoch et al. 1963, Brechignac \& Andre 1984, Sueltemeyer et al. 1986, Kana 1990), although it is not always a monotonic increase, especially in cyanobacteria. Grande (1988) noted an apparent light intensity effect on oligotrophic ocean samples. Much higher rates of oxygen cycling were observed in shipboard samples than in samples incubated in situ. They attributed this discrepancy to the fact that the samples aboard ship were exposed to higher light intensities.

Although relatively few algal or plant species have been studied using ${ }^{18} \mathrm{O}$ methodology, chl-specific rates of gross photosynthesis and (dark) respiration do vary among taxa (e.g. Laws 1975, Glover 1980, Falkowski 1981, Langdon 1988). Chl-specific photosynthesis rates will depend on the presence of non-chl accessory pigments and the optical properties of the cell or tissue. Values of assimilation numbers typically fall in the range 150 to $750 \mu \mathrm{MC}(\mu \mathrm{Mchl} a)^{-1} \mathrm{~h}^{-1}$, which equates to oxygen fluxes in the range 180 to $900 \mu \mathrm{mol} \mathrm{O} \mathrm{O}_{2}(\mu \mathrm{M}$ chl a) $)^{-1} \mathrm{~h}^{-1}$ assuming a photosynthetic quotient of 1.2 . Values reported here generally fell within this range. More specifically, chlorophytes and diatoms typically exhibit gross oxygen evolution. rates around $300 \mu \mathrm{mol}$ $\mathrm{O}_{2}(\mu \mathrm{M} \text { chl } a)^{-1} \mathrm{~h}^{-1}$ (Glover 1980, Sueltemeyer et al. 1986, Weger et al. 1989), whereas cyanobacteria often exceed $700 \mu \mathrm{mol} \mathrm{O}_{2}(\mu \mathrm{M} \mathrm{chl} a)^{-1} \mathrm{~h}^{-1}$ at light saturation
(Post 1986, Kana unpubl.). Such differences among taxa possibly explain the different rates observed in $<10$ and $>10$ um size fractions (Fig. 2).

\section{CONCLUSIONS}

The demonstrated sensitivity of the isotope dilution technique places it between the more sensitive (and more costly) $\mathrm{H}_{2}{ }^{18} \mathrm{O}$ technique and less sensitive membrane inlet mass spectrometry technique. It is an appropriate method for studying oxygen cycling in typical estuarine and productive coastal waters. The instrumentation has proven seaworthy (data not shown) allowing the technique to be used in areas accessible to boats or ships equipped with laboratories. Oxygen cycling rates measured by this method are within the range reported using the $\mathrm{H}_{2}{ }^{18} \mathrm{O}$ technique, and are almost always higher than those determined by the $\mathrm{L} / \mathrm{D}$ bottle method.

Acknowledgements. I thank W. C. Dennison for assistance with the Zostera marina experiment and S. Banahan for assistance with the oxygen titrations. I also thank P. M. Glibert and anonymous reviewers for comments on the manuscript. The work was supported by NSF grant OCE-8710903. Significant financial contribution from the Center for Environmental and Estuarine Studies for the purchase of the mass spectrometer is also gratefully acknowledged

\section{LITERATURE CITED}

Bender, M., Grande, K., Johnson, K., Marra, J., Williams, P. J. le B., Sieburth, J., Pilson, M., Langdon, C., Hitchcock, G., Orchardo, J., Hunt, C., Donaghay, P., Heinemann, K. (1987). A comparison of four methods for determining planktonic community production. Limnol. Oceanogr 32: 1085-1098

Blackburn, T H. (1979). Method for measuring rates of $\mathrm{NH}_{4}{ }^{+}$ turnover in anoxic marine sediments, using a ${ }^{15} \mathrm{~N}_{-}-\mathrm{NH}_{4}{ }^{+}$ dilution technique. Appl. environ. Microbiol. 37: 760-765

Brechignac, F., Andre, M. (1984). Oxygen uptake and photosynthesis of the red macroalga, Chondrus crispus, in seawater. Plant Physiol. 75: 919-923

Bunt, J. (1965). Measurements of photosynthesis and respiration in a marine diatom with the mass spectrometer and with carbon-14. Nature, Lond. 207: 1373-1375

Dugdale, R. C., Wallace, J. Z. (1960). Light and dark bottle experiments in Alaska. Limnol. Oceanogr. 5: 230-231

Falkowski, P. G. (1981). Light-shade adaptation and assimilation numbers. J. Plankton Res. 3: 203-216

Fuhrman, J. (1987). Close coupling between release and uptake of dissolved free amino acids in seawater studied by an isotope dilution approach. Mar. Ecol. Prog. Ser. 37 : $45-52$

Gaarder, T., Gran, H. H. (1927). Investigation of the production of plankton in the Oslo Fjord. Rapp. P.-v. Cons. int. Explor Mer 42: 1-48

Gieskes, W. W. C., Kraay, G. W. (1982). Effect of enclosure in large plastic bags on diurnal change in oxygen concentration in tropical ocean water Mar. Biol. 70:99-104 
Glibert, P. M., Lipschultz, F., McCarthy, J. J., Altabet, M. A (1982). Isotope dilution models of uptake and remineralization of ammonium by marine plankton. Limnol. Oceanogr. 27: 639-650

Glover, H. E. (1980). Assimilation numbers in cultures of marine phytoplankton. J. Plankton Res. 2: 69-79

Grande, K. D. (1988). The use of the stable isotope, oxygen-18, as a tracer to measure gross primary production in coastal and oligotrophic waters and in monoclonal cultures of marine phytoplankton. Ph. D. thesis, University of Rhode Island

Grande, K. D., Marra, J., Langdon, C., Heinemann, K., Bender, M. L. (1989). Rates of respiration in the light measured using an ${ }^{18} \mathrm{O}$ isotope-labelling technique. J. exp. mar. Biol. Ecol. 129: 95-120

Harris, G. P. (1980). The measurement of photosynthesis in natural populations of phytoplankton. In: Morris, I. (ed.) The physiological ecology of phytoplankton. Univ. California Press, Berkely, p. 129-187

Harris, G. P., Piccinin, B. B. (1977). Photosynthesis by natural phytoplankton populations. Arch. Hydrobiol. 80: 405-457

Helz, G. R., Kieber, R. J. (1985). Hydrogen peroxide in estuarine waters: a minor but significant contributor to chlorine demand. In: Jolley, R. L. et al. (eds.) Water chlorination, Vol. 5. Chemistry, environmental impact and health effects Lewis Publ., Chelsea, Michigan, p. 1033-1040

Hoch, G., Kok, B. (1963). A mass spectrometer inlet system for sampling gases dissolved in liquid phases. Arch. Biochem. Biophys. 101 160-170

Hoch, G., Owens, H., Kok, B. (1963). Photosynthesis and respiration. Arch. Biochem. Biophys. 101: 171-180

Kana, T. M. (1990). Rapid oxygen cycling in the marine nitrogen fixing cyanobacterium, Trichodesmium, measured by O-18 mass spectrometry. EOS $71: 164$

Laane, R. W. P. M., Gieskes, W W. C., Kraay, G. W., Eversdijk A. (1985). Oxygen loss from natural waters by photooxidizing processes. Neth. J. Sea Res. 19: 125-128

Lancelot, C., Mathot, S. (1985). Biochemical fractionation of primary production by phytoplankton in Belgian coastal waters during short- and long-term incubations with ${ }^{14} \mathrm{C}$ bicarbonate. 1. Mixed diatom populations. Mar. Biol. 86 219-226

Langdon, C. (1988). On the causes of interspecific differences in the growth-irradiance relationship for phytoplankton. II. A general review. J. Plankton Res. 10: 1291-1312

Laws, E. A. (1975). The importance of respiration losses in controlling the size distribution of marine phytoplankton. Ecology 56: 419-426

Miller, W. L., Kester, D. R. (1988). Hydrogen peroxide measurement in seawater by ( $p$-hydroxyphenyl)acetic acid dimerization. Analyt. Chem. 60: 2711-2715

Moffett, J. W. Zika, R. G. (1983). Oxidation kinetics of copper(I) in seawater: implications for its existence in the marine environment. Mar. Chem. 13: 235-251

Palenik, B., Zafiriou, O. C.. Morel, F. M. M. (1987). Hydrogen peroxide production by a marine phytoplankter. Limnol. Oceanogr. 32: 1365-1369

Pamatmat, M. M. (1988). Catalase activity and the hydrogen peroxide cycle. Arch. Hydrobiol. Beih. Ergebn. Limnol. 31 : $107-114$

Parsons, T R., Maita, Y., Lalli, C. M. (1984). A manual of

This article was submitted to the editor chemical and biological methods for seawater analysis. Pergamon Press, Oxford

Peltier, G., Thibault, P. (1985). O Optake in the light in Chlamydomonas: evidence for persistent mitochondrial respiration. Plant Physiol. 79: 225-230

Petasne, R. G., Zika, R. G. (1987). Hydrogen peroxide lifetimes in seawater. EOS 50: 1752-1753

Peterson, B. J. (1980). Aquatic primary productivity and the ${ }^{14} \mathrm{C}-\mathrm{CO}_{2}$ method: a history of the productivity problem. Ann. Rev. Ecol. Syst. 11: 359-385

Post, A. F. (1986). Transient state characteristics of adaptation to changes in light conditions for the cyanobacterium Oscillatoria agardhii. I. Pigmentation and photosynthesis. Arch. Microbiol. 145: 353-357

Radmer, R., Ollinger, O. (1980). Measurement of the oxygen cycle: the mass spectrometric analysis of gases dissolved in a liquid phase. Methods Enzymol. 69: 547-560

Raven, J. A., Beardall, J. (1981). Respiration and photorespiration. Can. Bull. Fish. Aquat. Sci. 210: 55-82

Smith, R. E. H., Geider, R. J., Platt, T (1984). Microplankton productivity in the oligotrophic ocean. Nature, Lond. 311: 252-254

Smith, R. E. H., Harrison, W. G., Irwin, B., Platt, T (1986). Metabolism and carbon exchange in microplankton of the Grand Banks (Newfoundland). Mar. Ecol. Prog. Ser. 34: 171-183

Strickland, J. D. H., Parsons, T. R. (1972). A practical handbook of seawater analysis. Bull. Fish. Res. Bd Can. 167

Sueltemeyer, D. F., Klug, K., Fock, H. P. (1986). Effect of photon fluence rate on oxygen evolution and uptake by Chlamydomonas reinhardtii suspensions grown in ambient and $\mathrm{CO}_{2}$-enriched air Plant Physiol. 81: 372-375

Szymczak, R., Waite, T D. (1988). Generation and decay of hydrogen peroxide in estuarine waters. Aust. J. mar Freshwat. Res. 39: 289-299

Turpin, D. H., Elrifi, I. R., Birch, D. G., Weger, H. G., Holmes, J. J. (1988). Interactions between photosynthesis, respiration, and nitrogen assimilation in microalgae. Can. J. Bot. 66: 2083-2097

Van Baalen, C., Marler, J. E. (1966). Occurrence of hydrogen peroxide in seawater. Nature, Lond. 211: 951

Weger, H. G., Herzig, R., Falkowski, P. G., Turpin, D. H. (1989). Respiratory losses in the light in a marine diatom: measurements by short-term mass-spectrometry. Limnol. Oceanogr. 34: 1153-1161

Weisburd, R. S. J., Laws, E. A. (1988). Diumal variation of respiration rates in shallow eutrophic ponds. EOS 69: 1126

Williams, P. J. le B., Heinemann, K. R., Marra, J., Purdie, D. A. (1983). Comparison of ${ }^{14} \mathrm{C}$ and $\mathrm{O}_{2}$ measurements of phytoplankton production in oligotrophic waters. Nature, Lond. 305: 49-50

Vollenweider, R. A. (ed.) (1969). A manual on methods for measuring primary production in aquatic environments Blackwell, Oxford

Zika, R. G., Moffett, J. W., Cooper, W. J., Petasne, R. G., Saltzman, E. S. (1985). Hydrogen peroxide concentration and distribution in the Gulf of Mexico and West Florida shelf. Geochirn. Cosmochim. Acta 49: 1173-1184

Manuscript first received: February 13, 1990

Revised version accepted: April 10, 1990 